\title{
Revista \\ Brasileira \\ A presença de familiares na sala de quimioterapia pediátrica
}

\author{
The presence of family members in the pediatric chemotherapy room \\ La presencia de miembros de la familia en la sala de quimioterapia pediátrica
}

\begin{abstract}
Isabelle Pimentel Gomes', Daniela Doulavince Amador", Neusa Collet"I
' Universidade Federal da Paraíba, Programa de Pós Graduação em Enfermagem (Doutoranda). João Pessoa-PB, Brasil.

"Universidade Federal da Paraíba, Programa de Pós Graduação em Enfermagem (Mestranda). João Pessoa-PB, Brasil.

II' Universidade Federal da Paraíba, Departamento de Enfermagem de Saúde Pública e Psiquiatria,

Programa de Pós-Graduação em Enfermagem. João Pessoa-PB, Brasil.
\end{abstract}

Submissão: 27-08-2011 Aprovação: 27-11-2012

\section{RESUMO}

Objetivou-se analisar as necessidades do familiar acompanhante na sala de quimioterapia do ponto de vista da criança em tratamento. Estudo qualitativo, realizado em um hospital escola da cidade do Rio de Janeiro, entre abril e junho de 2010. Utilizou-se adaptação da técnica do desenho-estória temático para produção do material empírico junto a sete crianças. A análise foi feita utilizando-se a interpretação temática. As necessidades do familiar para a criança em tratamento são: estímulo para o rodízio entre os membros da família como cuidador da criança; orientação e treinamento para os diferentes membros da família que acompanham as crianças; conforto para o familiar permanecer ao lado da criança; autonomia para o familiar; acolhimento ao irmão saudável; ambiente que proporcione aproximação entre os pais separados para apoiar o filho em tratamento. Torna-se imprescindível a ampliação do foco assistencial restrito à criança com câncer, expandindo a atenção da equipe de enfermagem aos familiares.

Descritores: Família; Enfermagem Pediátrica; Neoplasias; Quimioterapia.

\begin{abstract}
The purpose was to analyze the needs of the family companion that follows the child in the chemotherapy unit from the standpoint of the child in treatment. It was a qualitative study. We used the adaptation of drawing-story with themes for the production of empirical data from seven children with cancer. The analysis was done using a thematic interpretation. For children, the family needs are: to incentive to change among family members as caregivers of the child; counseling and training for all family members who accompany the children; comfort for the family to remain with the child; autonomy for the family; take care the healthy sibling; environment that provides closeness between unmarried parents to support the child in treatment. It is essential to expand the focus of care restricted to children with cancer, broadening also the attention of nursing `s team to family.
\end{abstract}

Key words: Family; Pediatric Nursing; Neoplasms; Drug Therapy.

\section{RESUMEN}

El objetivo fue analizar las necesidades del familiar acompañante en la sala de quimioterapia desde el punto de vista de los niños en tratamiento. Estudio cualitativo. Se utilizó la técnica de lo diseño estoria con tema para recoletar datos con siete niños con cáncer. El análisis se realizó mediante una interpretación temática. Para los niños las necesidades de la familia son: estímulo a lo intercambio entre los miembros de la familia como los cuidadores del niño; orientación y capacitación para los diferentes miembros de la familia que acompañan a los niños; comodidad para la familia a permanecer con el niño; autonomía de la familia; cuidado de lo hermano sano; medio ambiente proporciona la aproximación entre los padres divorciados. Es esencial ampliar el foco de atención del equipo de enfermería limitada a los niños con cáncer para la familia.

Palabras clave: Familia; Enfermería Pediátrica; Neoplasias; Quimioterapia. 


\section{INTRODUÇÃO}

A quimioterapia ambulatorial é uma alternativa para minimizar danos relacionados à quebra de vínculos familiares, uma vez que a criança passa a ter possibilidade de receber o tratamento proposto e ser liberada para retornar ao lar após algumas horas $^{(1)}$. No entanto, mesmo a quimioterapia ambulatorial, possível para alguns tipos de câncer infantil, traz consigo repercussões que fragilizam e vulnerabilizam a criança e sua família $^{(2)}$. O tratamento do câncer geralmente é acompanhado por dor e sofrimento para a criança e família que estão relacionados, muitas vezes, ao processo do adoecer, à necessidade de idas frequentes ao hospital, aos procedimentos invasivos, alterações do corpo e estado emocional.

Os possíveis efeitos colaterais da quimioterapia são inúmeros. Um estudo identificou que entre os sintomas mais desconfortáveis, sob o ponto de vista de crianças em tratamento, estão: náuseas e vômitos, aumento do peso, dor, reação de hipersensibilidade, fadiga e febre, os quais interferem diretamente no cotidiano delas levando à diminuição do estado de bem estar e, consequentemente, piora na qualidade de vida ${ }^{(3)}$.

Diante de todas as adversidades do tratamento, os membros da família representam para a criança o seu primeiro recurso de enfrentamento da situação. Por meio da afetividade eles desempenham um papel essencial para o desenvolvimento da criança. O diagnóstico de câncer torna-se uma ameaça à vida da criança e à segurança da família(2).

Atualmente, os cuidados de enfermagem em oncologia pediátrica estão voltados para a implementação de protocolos de pesquisa clínica, educação das famílias sobre efeitos colaterais agudos e crônicos da quimioterapia e da radiação, e prestação de cuidados, de apoio psicossocial, como um meio ideal para melhorar a qualidade de vida da criança durante o tratamento e sua sobrevivência ${ }^{(4)}$. Isso mostra que as ações de enfermagem voltam-se para o acompanhamento do quadro clínico da criança e os avanços da oncologia, que exigem muita atenção especializada. No entanto, ainda é um desafio a prestação de um cuidado singular de alta qualidade às crianças e suas famílias ${ }^{(2)}$.

O cuidado em oncologia pediátrica não se limita a realização do procedimento, sobretudo inclui o componente emocional, o aspecto cognitivo, da percepção, do conhecimento e inclusive a intuição, desenvolvendo habilidade para ajudar as crianças e seus familiares a encontrarem os seus potenciais e lidarem com as adversidades ${ }^{(3)}$. A busca pela melhoria do cuidado inicia-se ao ouvir os receptores do cuidado, considerando sua visão, pois ele é quem mais reconhece suas necessidades relacionadas com bem estar e valores humanos. Reconhecendo os familiares como recurso de enfrentamento das adversidades ligadas ao diagnóstico e tratamento da criança, objetiva-se analisar as necessidades do familiar acompanhante na sala de quimioterapia do ponto de vista da criança em tratamento.

\section{METODOLOGIA}

Trata-se de estudo qualitativo, descritivo, exploratório, realizado em um hospital escola localizado na cidade do Rio de
Janeiro. Utilizou-se uma adaptação da técnica do desenho-estória com tema para a coleta do material empírico. Esta técnica constitui-se na reunião de processos expressivos-motores (o desenho), processos aperceptivos-dinâmicos (verbalizações temáticas) e associações dirigidas do tipo inquérito ${ }^{(5)}$. Esse é um recurso por meio do qual a criança tem possibilidade de produzir discursos sobre tudo que envolve a sua vida, sua história, sua visão de mundo, revelando sua maneira própria de ver e de pensar a realidade ${ }^{(6)}$. A adaptação da técnica se deu pelo fato de não considerar como material para interpretação o desenho, utilizou-se apenas os relatos. Realizou-se teste piloto para validação da técnica.

O número total de sujeitos não foi estipulado a priori; foi definido ao longo do processo de pesquisa, segundo critério de suficiência, isto é, quando o julgamento de que o material empírico permite traçar um quadro compreensivo da questão investigada $^{(7)}$. Com isso o total de sujeitos incluídos no estudo foi de sete crianças.

Os critérios de inclusão dos sujeitos foram: crianças que fizeram ou que estavam fazendo quimioterapia ambulatorial; faixa etária escolar, entre 6 e 12 anos; ter condições físicas e emocionais (sem chorar, calmo e tranquilo) para se comunicar verbalmente e desenhar. As condições físicas foram avaliadas de acordo com a escala de desempenho ECOG (Eastern Cooperaative Oncology Group) ${ }^{(8)}$, a qual proporciona segurança de não incluir sujeitos incapacitados fisicamente para realizar as atividades propostas pela pesquisadora. Assim, assegurou-se maior confiabilidade na seleção dos sujeitos, garantindo maior rigor, sem expor desnecessariamente, crianças sem condições de participar do estudo, protegendo, dessa forma, as que estivessem com estado físico comprometido.

O procedimento de coleta do material empírico foi realizado no período de abril a junho de 2010, individualmente, no turno da manhã, na sala de quimioterapia da instituição, conhecida como Aquário Carioca, sem a presença do responsável pela criança. Seguiu-se da seguinte forma: a criança foi convidada a sentar-se próxima a uma mesa e a pesquisadora sentou-se a sua frente, colocou-se lápis coloridos espalhados sobre a mesa e uma folha de papel. Solicitou-se à criança que fizesse um desenho livre: "Você tem essa folha em branco e pode fazer o desenho que quiser". Aguardou-se a conclusão do primeiro desenho. Após a conclusão a pesquisadora solicitou: "Você, agora, olhando o desenho, pode criar uma estória, dizendo o que acontece". Solicitou-se esclarecimentos necessários à compreensão e à interpretação do material que foi produzido tanto no desenho quanto na estória (fase de inquérito). A seguir foi solicitado que o sujeito fizesse o desenho de uma criança fazendo quimioterapia e após a conclusão solicitou-se: "Você pode contar a estória de uma criança recebendo quimioterapia". Concluída a fase de contar estórias, passou-se ao "inquérito". Nesta, utilizou-se as segintes questões norteadoras: "Quem vem com esta criança para o hospital?"; "Você poderia me contar o que acontece com essa pessoa enquanto a criança recebe a quimioterapia?". À medida que estas questões foram exploradas outras foram formuladas, para aprofundar mais as informações, tais como: "Pode me explicar melhor?", "Como assim?". A técnica foi 
utilizada com a finalidade de compreender a percepção da criança a respeito do tema por meio do estímulo de contar as estórias. Todo o procedimento foi gravado, após autorização do responsável e da criança e transcrito na íntegra, logo após sua realização, para que não fossem perdidos detalhes.

Utilizou-se a interpretação temática ${ }^{(7)}$ para análise dos relatos. Portanto, após a transcrição das entrevistas gravadas procedeu-se uma primeira organização dos relatos em determinada ordem, já iniciando uma classificação. Posteriormente, realizou-se leitura exaustiva e repetida dos textos, fazendo uma relação interrogativa com eles para apreender as estruturas de relevância. Em seguida, a partir das estruturas de relevância, processou-se o enxugamento da classificação, reagrupando os temas mais relevantes para proceder a análise final.

Foram respeitados os aspectos éticos preconizados pela Resolução No 196/96 do Ministério da Saúde ${ }^{(9)}$ e também a Resolução No 311/07 do Conselho Federal de Enfermagem ${ }^{(10)}$. O projeto foi aprovado pelo Comitê de Ética em Pesquisa da Instituição em 30 de março de 2010, sob o memorando de número 56/09. Os responsáveis pelas crianças assinaram o Termo de Consentimento Livre e Esclarecido. Utilizou-se nomes fictícios para as crianças garantindo o anonimato dos sujeitos.

Para ilustrar a apresentação dos resultados, selecionamos alguns trechos das falas dos participantes e utilizamos a seguinte padronização: os colchetes com reticências [...] significam supressão nos discursos feitas pela pesquisadora; os parênteses ( ) estão preenchidos com intercalações do pesquisador com intenção de contextualizar o que foi falado pela criança.

\section{RESULTADOS E DISCUSSÃO}

Não se concebe receber uma criança para tratamento quimioterápico sem ser acompanhada por um responsável, tendo em vista que ela passará por procedimentos invasivos, muitas vezes dolorosos e que podem trazer sofrimento e desconforto para a criança. A presença de uma pessoa significativa para a criança, em geral seus pais ou parentes próximos parece ser benéfica sob a ótica da criança, pois ela os inclui como essenciais ao tratamento ambulatorial. A segurança emocional é manifestada na presença de alguém em quem a criança confia e que tem vínculo afetivo.

Poderia ser com a mãe, com o pai, com a tia, com o avô, com a avó. [...] A minha tia quem me traz, ela sabe de tudo, da consulta, dos remédios, de tudo... (Rosa, 10 anos).

Os pais. [...] ao lado dela (criança). Na cadeira ao lado (Branco -8 anos).

Minha mãe nunca vem, ela é separada. Eu moro com o meu pai, ele quem cuida de mim e me traz para o Aquário. Sempre o meu pai (Verde 11anos).

A possibilidade de diferentes membros da família acompanhar as crianças é positiva, pois passa a não sobrecarregar uma única pessoa. O rodízio entre cuidadores da criança precisa ser levado em consideração para o cuidado de enfermagem, pois mesmo que haja comunicação entre eles pode ser que nem todos tenham o mesmo conhecimento em relação à doença e tratamento. Tal fato pode influenciar diretamente na qualidade do cuidado prestado à criança. Torna-se primordial que a equipe de saúde esteja atenta para identificar se há fragilidades no cuidado que interfiram negativamente na tomada de decisões diante da necessidade da criança. Para isso, um estudo ${ }^{(2)}$ sugere que orientação, treinamento e esclarecimento de dúvidas possibilita aos diferentes cuidadores que se sintam seguros ao assumir esta função. Nesse sentido, deve ser avaliado o processo de enfrentamento dos diferentes membros, pois eles passam por sofrimento com o diagnóstico da criança.

Mesmo o tratamento sendo realizado apenas durante algumas horas e a criança e seu familiar serem liberados para retornar ao lar, permanecer sentado durante toda a infusão da quimioterapia pode ser desconfortável. Estimular a presença do familiar ao lado da criança é uma prática que pode ser positiva, mas para isso é importante disponibilizar cadeiras confortáveis, bem como opções de distrações não só para a criança, mas também para o adulto.

A minha mãe sempre fica comigo aqui no Aquário quando estou fazendo quimioterapia ou punção lombar (Roxo - 6 anos).

Minha mãe fica lá fora (recepção) [...] Não tenho medo (Preto - 7 anos).

A certeza de que a mãe está próxima, mesmo que não seja ao lado, mas que é facilmente alcançável faz com que a criança se sinta segura, fato este que possibilita a autonomia e independência para ambos. Manter-se ao lado da criança durante toda a infusão da quimioterapia pode ser cansativo e entediante, sair um pouco da sala e interagir com outros familiares ou profissionais da saúde, mais distante da criança, pode ser agradável e até mesmo lúdico e encorajador. Autores $^{(11)}$ revelam que a família pode ser considerada um dos principais precursores da amenização dos efeitos negativos acarretados pela dor, medo e insegurança advindos da experiência da criança no hospital. Contudo, identificou-se, neste estudo, que para estarem fortalecidos para apoiar a criança, é fundamental que os familiares encontrem um contexto que os incluam como agentes ativos e participativos no processo de cuidar, de forma que o cuidador consiga sentir-se acolhido e orientado quanto às condutas no contexto hospitalar:

Aqui (no Aquário) eu não passava mal não. Só um dia que uma mãe (de outra criança) deixou uma comida aberta, eu senti o cheiro e comecei a passar mal (Azul-11 anos).

O relato de Azul enfatiza que a atitude da mãe de outra criança ao deixar uma bandeja de refeição aberta o incomodou, pois ele estava recebendo uma medicação com potencial emético. Este é um aspecto que merece atenção da 
Enfermagem para intervir de forma a orientar os familiares sobre atitudes e comportamentos que podem gerar desconforto para a criança que está acompanhando, assim como as demais que frequentam o mesmo espaço. Autores ${ }^{(3)}$ comentam que este é um ponto que a Enfermagem deve observar para intervir de forma a preservar o ambiente livre de odores, pois as comidas com cheiro forte são evitadas por crianças e adolescentes em quimioterapia, sendo esta uma estratégia para minimizar as náuseas e vômitos. Uma medida sugerida pelos autores $^{(3)}$ é evitar abrir as bandejas de refeição dentro da sala de aplicação das medicações, onde ficam as crianças.

Para receber os famíliares na sala de quimioterapia ambultorial toda a equipe de saúde precisa estar preparada para atender às suas necessidades singulares, acolhendo-os com seus problemas, o que pode ser exemplificado no depoimento a seguir:

Eu tenho um irmão mais novo. Ele já veio aqui no Aquário (sala de quimioterapia). Ele fica brincando lá na frente (reсерção) [...] (Verde - 11 anos).

O familiar cuidador pode ficar dividido, pois a criança saudável não deve permanecer na sala que o irmão recebe a quimioterapia, pois se trata de um ambiente insalubre, pelo risco de contaminação química. Ao mesmo tempo, existe a dificuldade de deixar seu filho saudável sozinho em um ambiente desconhecido, com pessoas que a criança não está familiarizada, enquanto acompanha o outro durante realização de procedimentos invasivos como punção venosa ou de cateter, punção lombar, mielograma, entre outros. Quando a família necessita distanciar-se do filho saudável, há um sofrimento para ambos, os pais por sentirem-se culpados e os filhos por verem a atenção de seus progenitores diminuída. Estudo ${ }^{(12)}$ revela que a reação dos irmãos saudáveis face à crescente atenção dos pais com o filho doente pode manifestar-se através de ciúmes, preocupação, ansiedade e instabilidade emocional, inclusive com o surgimento de uma agressividade até então inexistente. Nesses casos, atender às particularidades da família contribui para minimizar o estresse desencadeado pela necessidade de reorganização da dinâmica familiar.

[...] O meu pai traz a gente (a criança em tratamento e seu irmão) quando a babá falta ou quando ela chega tarde, porque não tem com quem deixar meu irmão. Meus pais são separados. (Verde - 11 anos).

Em alguns casos, quando há separação conjugal entre os pais, como referido por Verde, a família pode ter mais um desafio e precisa buscar soluções para se adaptar às imposições da condição crônica que, neste caso, é a necessidade de ir ao hospital para receber o tratamento. Autores ${ }^{(13,14)}$ concordam que a relação entre os pais da criança com câncer geralmente sofre abalos. Toda a tensão provocada pela situação do filho, faz com que o casal esqueça de sua vida conjugal e desloque toda a sua atenção e energia para os cuidados ao filho doente, o que pode resultar em sérios problemas no relacionamento do casal ${ }^{(13)}$.

A estratégia utilizada, diante de tal abalo na relação conjugal, de acordo com o relato da criança, por esse pai foi levar os dois filhos para o hospital, de forma que o portador de câncer não deixe de receber a medicação. A equipe de enfermagem em sua prática clínica deve atentar para promover o apoio social e acolhimento aos irmãos saudáveis de crianças portadoras de câncer ${ }^{(12)}$. Evidencia-se que a doença grave na criança pode fragilizar os vínculos familiares anteriormente estabelecidos, porque ela gera uma série de sentimentos e situações que podem desestabilizar uma família ${ }^{(14)}$.

Os outros filhos sofrem com isso, não só por verem seu irmão doente, mas porque veem as atenções dos pais com eles diminuídas, facilmente têm consciência de que há desestabilização na família, bem como um certo isolamento social ${ }^{(15)}$. Por esses motivos há autores ${ }^{(16)}$ que referem os irmãos saudáveis como a criança "invisível". Tais fatos podem interferir diretamente no desenvolvimento da criança saudável. Os irmãos percebem mudanças em seu cotidiano, que não será o mesmo por muito tempo. Eles podem apresentar alterações negativas de ordem psicológica e problemas psicossociais, tais como reações negativas, tristeza, desamparo e dificuldades na escola ${ }^{(16)}$, mas, por outro lado, pode estimular uma prematuridade com o desenvolvimento de estratégias pessoais para enfrentamento da crise familiar. Neste estudo percebeu-se que é possível haver uma espécie de acordo entre os pais para que, mesmo separados, possam acompanhar de perto o filho nessa fase de sua vida, estando próximos e se fazendo presentes:

Eu vinha com o meu pai, depois minha mãe chegava para ficar comigo também (os pais são separados). Só ficava minha mãe (dentro da sala). Quando a minha mãe não podia vim o meu pai ficava comigo (dentro da sala) (Azul - 11 anos).

No caso anterior, identifica-se união entre os pais da criança de forma que conflitos anteriores deixam de prevalecer diante da condição crônica do filho, exigindo maior interação e comunicação em busca de oferecer carinho, atenção e fortalecimento ao filho durante as infusões de quimioterapia. Os pais se mobilizam para lutar contra o câncer, seguir em frente com o tratamento, objetivando oferecer o melhor para a criança.

Corroborando os achados, a literatura ${ }^{(12,14)}$ mostra que a criança com doença oncológica pode desencadear disfuncionalidades previamente existentes (aparentemente sanadas) ou até então inexistentes no ambito familiar, mas, sobretudo, pode ser um fator de coesão na família. Autores ${ }^{(14)}$ afirmam que há modificações na dinâmica e nas relações, que podem estimular a união das pessoas da família, fazendo com que elas se mobilizem para acolher a criança, assim como foi identificado no relato a cima.

Os resultados mostram que se torna imprescindível a ampliação do foco assistencial restrito à criança com câncer, expandindo a atenção da equipe de enfermagem à família. A família, para a equipe de saúde, pode representar uma unidade de colaboração o que reverterá em eficácia e eficiência do cuidar $^{(2,17)}$. O familiar forma um vínculo com a criança e encoraja o desenvolvimento da confiança mútua, de uma orientação positiva, de um equilíbrio evolutivo, de poder responsivo à ação em favor da criança em desenvolvimento ${ }^{(14)}$, que a 
beneficia no seu processo de enfrentamento. Nesse sentido, um projeto terapêutico centrado na criança e sua família estará comprometido com as mudanças necessárias nos modos de organização do processo de trabalho em saúde na atenção à criança com câncer que se restringem a cuidar da doença, sobretudo no resgate da dimensão cuidadora ampliada dos sujeitos envolvidos.

A oportunidade de poder interagir, falar e desta forma até simbolizar todas as angústias sofridas proporciona o estreitamento dos vínculos e, com isso, um melhor enfrentamento da situação, resultando em uma atitude mais cooperativa em relação ao tratamento ${ }^{(13)}$.

O enfermeiro desempenha um papel fundamental, quando é um vínculo apoiador para as crianças e os integrantes da família. As ações que compõem este papel de fornecer apoio são parte do cuidado integral(14). A equipe de enfermagem deve estimular, por meio do diálogo, a criação de vínculos apoiadores no contexto intra e extrafamiliar e de espaços que possibilitem a construção, a troca e a reconstrução de saberes, como meios para alcançar essas oportunidades ${ }^{(18)}$. O envolvimento na participação do cuidado nem sempre acontece na mesma dimensão para todos os membros da família e para que o cuidador principal não seja sobrecarregado com privações, estresses, desgastes, tensão e fadiga, devido sua dedicação ao cuidado à criança com câncer, o que pode interferir diretamente na sua qualidade de vida e condição de saúde, é essencial o fortalecimento do apoio social.

É preciso olhar para o não dito, perceber o imperceptível, compreender o que se oculta atrás das palavras, entender os processos do diagnóstico aos cursos que a doença pode seguir, a cura ou a morte, sendo capaz de auxiliar os familiares envolvidos com o cuidado à criança nesse momento de fragilidade e insegurança. $\mathrm{O}$ conhecimento insuficiente desses aspectos poderá levar o profissional a um distanciamento da criança e sua família como uma forma de proteção por não saber enfrentar tal situação, promovendo falha na prestação do cuidado singular/integral tão almejado pela Enfermagem ${ }^{(19)}$.

A apreensão da relação de proximidade dessas crianças com seus familiares durante o tratamento quimioterápico indica a premência de a equipe de enfermagem atuar no fortalecimento dos vínculos existentes. Tal ação pode se dá por meio do diálogo constante que vise o esclarecimento das dúvidas, o compartilhamento de experiências e a participação conjunta no cuidar. Essa direcionalidade na produção do cuidado permite atender as demandas dos familiares de modo que se sintam confortáveis e encorajados a permanecer na luta contra o câncer, enquanto acompanhante durante as seções de quimioterapia ambulatorial, ou de forma que se apropriem de ferramentas essenciais para o cuidado do filho com câncer.

\section{CONSIDERAÇÕES FINAIS}

Foi possível identificar por meio do relato das crianças, lacunas existentes no cotidiano dos familiares que as acompanham durante a quimioterapia ambulatorial, que são essenciais para fundamentar um cuidado de enfermagem centrado na criança e família, tais como: estímulo para o rodízio entre os membros da família como cuidador da criança; orientação e treinamento para os diferentes membros da família que acompanham as crianças no tratamento ambulatorial; conforto para o familiar permanecer ao lado da criança durante as horas de tratamento; autonomia para o familiar durante as infusões das medicações; acolhimento ao irmão saudável; ambiente que proporcione aproximação entre os pais separados para apoiar o filho em tratamento.

Diante de todas as necessidades que permeiam o cotidiano do familiar, torna-se evidente a relevância de a enfermagem desenvolver habilidades de "pensar família", entendendo-a como sistema que demanda apoio, atenção e cuidado. A família é o sistema mais importante que a criança pertence e as relações familiares são cruciais para o adequado enfrentamento da doença e do tratamento prolongado.

Centrar o cuidado na criança e na sua família implica ir além dos aspectos clínicos, mas compreender as repercussões psicológicas e sociais desse binômio. É indispensável que essa relação seja permeada pela confiança mútua, pautada em um modo de cuidar que vislumbre a união dos saberes e vivências profissionais e da família. A apreensão e compreensão das necessidades dos familiares, sob a ótica da criança, contribue para a implementação de estratégias de intervenção na sala de quimioterapia e na sala de espera, levando-se em conta as especificidades do contexto de cada familiar.

\section{REFERÊNCIAS}

1. Gomes IP, Reis PED, Collet N. Gerenciando o cuidado de enfermagem no ambulatório de quimioterapia pediátrica: relato de experiência. Rev Enferm UFPE Online [periódico na internet]. 2010 [acesso em 18 set 2010];2(4):61-7 Disponível em: < http://www.ufpe.br/revistaenfermagem/ index.php/revista/article/view/646/pdf_42>

2. MacKay LJ, Gregory D. Exploring Family-Centered Care Among Pediatric Oncology Nurses. J Pediatr Oncol Nurs 2011;28(1):43-52.

3. Gomes IP, Collet N. Distressful symptoms related to chemotherapy from the perspective of children: a qualitative research. Online Braz J Nurs [periódico na internet]. 2010 [acesso em 18 set 2010]; 9(2) Disponível em: <http:// www.objnursing.uff.br/index.php/nursing/article/ view/j.1676-4285.2010.3045/683>

4. Cantrell MA. The art of pediatric oncology nursing practice. J Pediatr Oncol Nurs 2007; 24(3):132-8.

5. Trinca W. Investigação clínica da personalidade: o desenho livre como estímulo de apercepção temática. 3 ed. São Paulo: EPU; 2003.

6. Francischini R, Campos HR. Crianças e infâncias, sujeitos de investigação: bases teórico-metodológicas. In: Cruz 
SHV. A criança fala: a escuta de crianças em pesquisa. São Paulo: Cortez; 2008.

7. Minayo MCS. O desafio do conhecimento: pesquisa qualitativa em saúde. 11. ed. São Paulo: Hucitec; 2008.

8. Ministério da Saúde, Instituto Nacional de Câncer. Ações de enfermagem para o controle do câncer: uma proposta de integração ensino-serviço. Rio de Janeiro: INCA; 2008.

9. Ministério da Saúde (Brasil). Resolução n . 196, de 10 de outubro de 1996. Dispõe sobre diretrizes e normas regulamentadoras de pesquisas envolvendo seres humanos. Diário Oficial da União 10 out 1996.

10. Conselho Federal de Enfermagem (Brasil). Resolução $\mathrm{n}^{\circ}$ 311, 8 de fevereiro de 2007. Aprova a Reformulação do Código de Ética dos Profissionais de Enfermagem [resolução na internet] Diário Oficial da União 8 fev 2007. [acesso em 18 set 2010]. Disponível em: < http://www.portalcofen.gov.br/ 2007/materias.asp?ArticleID $=7221 \&$ sectionID $=34>$

11. Bortolote GS, Brêtas JRS. O ambiente estimulador ao desenvolvimento da criança hospitalizada. Rev Esc Enferm USP 2008;42(3):422-9.

12. Cardoso FT. Câncer infantil: aspectos emocionais e atuação do psicólogo. Rev Soc Bras Psicol Hosp 2007;10(1):25-52.
13. Pedro ICS, Galvão CM, Rocha SMM, Nascimento LC. Apoio social e famílias de crianças com câncer: revisão integrativa. Rev Latino-Am Enferm 2008,16(3):477-83.

14. Di Primio AO, Schwartz E, Bielemann VLM, Burille A, Zillmer JGV, Feijó AM. Rede social e vínculos apoiadores das famílias de crianças com câncer. Texto \& Contexto Enferm 2010; 19(2):334-42.

15. Azeredo Z, Amado J, Silva HNA, Marques IG, Mendes MVC. A família da criança oncologica. Acta Med Port 2004; 17(5):375-80.

16. Hagedoorn ME, Kreicbergs $U$, Appel C. Coping with cancer: The perspective of patients'relatives. Acta Oncol 2011;50(2):205-11.

17. Gomes GC, Erdmann AL, Busanello J. Refletindo sobre a Inserção da Família no Cuidado à Criança Hospitalizada. Rev Enferm UERJ 2010;18(1):143-7.

18. Araújo YB, Collet N, Gomes IP, Nobrega RD. Enfrentamento do adolescente em condição crônica: importância da rede social. Rev Bras Enferm 2011;64(2):281-6.

19. Sousa DM, Soares EO, Costa KMS, Pacífico ALC, Parente ACM. A vivência da enfermeira no processo de morte e morrer dos pacientes oncológicos. Texto \& Contexto Enferm 2009;18(1):41-7. 